\title{
Clinical Outcomes and Complications After Pedicle-anchored Dynamic or Hybrid Lumbar Spine Stabilization A Systematic Literature Review
}

\author{
Marion Prud'homme, MSc, ${ }^{*}$ Carlos Barrios, MD, $\dagger$ Philippe Rouch, PhD,* \\ Yann Philippe Charles, MD, $\$$ Jean-Paul Steib, MD, $\$$ and Wafa Skalli, PhD*
}

Study Design: A systematic medline review.

Objective: An overview of pedicle-based dynamic stabilization devices clinical outcomes.

Summary of Background Data: Fusion is the standard instrumentation for many pathologies of the lumbar spine. Worrying rates of failure, including adjacent segment degeneration (ASD), have consistently been reported. The interest for dynamic stabilization came from the need of minimizing the longterm complications related to the restriction of the lumbar motion. However, pedicle-based dynamic stabilization advantages and drawbacks remain controversial.

Materials and Methods: Articles about the clinical outcomes were identified by a comprehensive Medline search. The inclusion criteria were a minimum follow-up of 12 months, indications for lumbar dynamic stabilization, and assessment of clinical outcomes and adverse events. The studied parameters included self-reported outcomes (pain, disability, and satisfaction) and complications.

Results: A total of 46 articles fulfilling the inclusion criteria were reviewed providing results for 2026 patients with a mean followup of 33 months. The postoperative improvements in terms of pain and disability were significant. Subjective assessment showed an overall patient satisfaction of $83.4 \%$. Radiographic ASD occurred in $0 \%-34 \%$ of patients. Device breakage occurred in $0 \%-30 \%$, and device loosening in $0 \%-72 \%$ of patients. The global amount of revision surgeries reached $9.4 \%$ mainly for breakage, ASD, or persistent pain, not always associated with screw loosening.

\footnotetext{
*Laboratoire de Biomécanique, Arts et Métiers ParisTech,
}

Paris, France; †Institute for Research on Musculoskeletal Disorders, Valencia Catholic University, Valencia, Spain; and $\ddagger$ Department of Spine Surgery, University Hospital of Strasbourg, Strasbourg, France.

M.P. is financed for her $\mathrm{PhD}$ in biomechanics by a company marketing a dynamic stabilization device.

The authors declare no conflict of interest.

Reprints: Marion Prud'homme, MSc, Laboratoire de Biomécanique, Arts et Métiers ParisTech, LBM, 151 bd de l'hôpital, Paris 75013, France (e-mail: marion.prudhomme@ensam.eu).
Conclusions: Dynamic stabilization seems as safe and effective but benefits might partly come from decompressive gestures. Reported clinical outcomes seems to be comparable with outcomes published for fusion and no clear evidence of protection of the adjacent segments emerge from this mid-term review. Technical failures are design related but also linked with patient specificities. Relationships between sagittal balance and surgery outcomes are still rarely reported. Dynamic stabilization might display advantages in selected indications, such as moderate degeneration and beginning instability associated with clinical symptoms, but further clinical studies are needed.

Key Words: dynamic stabilization, clinical outcomes, screw loosening, adjacent segment degeneration, device failure

A fusion is the most frequently used technique to instrument the lumbar spine, the question of dynamic stabilization arose about 2 decades ago with the yearning for a more physiological and balanced proposal for patients. ${ }^{1}$ The maintenance of mobility at the instrumented segment is intended to transfer less loads at the adjacent segment thus decreasing the occurrence of adjacent segment degeneration (ASD) sometimes reported for rigid fusion devices. Several innovative concepts broke through such as total disk replacement, interspinous devices, or pedicle screw-based posterior devices. They have the common aim to maintain an anatomic-like flexibility of the vertebral segment but their inner functioning, their indications, and their surgical techniques differ. This review will only address the pedicle-based dynamic stabilization (PBDS) devices.

Until now the common indications of PBDS are moderate disk degeneration (Pfirrmann grade III or IV), mild facet osteoarthritis, low-grade spondylolisthesis, lumbar segmental instability, and dynamic stenosis, associated with clinical symptoms. The hybrid use of dynamic stabilization (1 flexible level adjacent to fused levels) aims to create a transition between a fused segment, a moderately degenerated segment, and the noninstrumented spine. Biomechanical reviews have demonstrated the impact of PBDS devices on the motion 
of the lumbar spine. ${ }^{2}$ A reduction in the range of motion is expected to protect the instrumented segment without transferring all the loading on the adjacent segment. However, there is still no clear clinical evidence that PBDS has better clinical results than fusion, and the controversy remains.

Several studies have addressed issues linked with nonfusion devices such as screw loosening ${ }^{3}$ or ASD. ${ }^{4}$ However, the biomechanical and clinical impacts of implant failure are not clear to date.

The purpose of the current review is to give a global overview of the clinical outcomes of PBDS devices, and to list and analyze the specific device-related complications. Reviews about posterior fusion, as the gold standard, are used as an element of comparison.

\section{MATERIALS AND METHODS}

\section{Literature Search Protocol}

A Medline search was performed using the query described in Figure 1 to find the articles published before January 10, 2013, about the clinical outcomes of dynamic stabilization devices. The reading of each title and abstract enabled the author to delete every publication that was not corresponding to the objectives of the review. The inclusion criteria for the selection were:

- Clinical study except from case reports.

- Indication for lumbar surgery.

- At least 1 group operated with a PBDS device used for dynamic stabilization.

The exclusion criteria were:

- Text of the article not written in English, French, Spanish, or German.

- Impossibility to determine the device used.

- Mean follow-up lower than 12 months.

- Patients already enrolled in another selected study with a longer term follow-up or a larger patient cohort.

- No mention of visual analog scale (VAS) or Oswestry Disability Index (ODI) nor remarks about the rate of complications during or after the surgery.

- Instrumentation with the Graf ligament because of a limitation of hyperflexion only, which is significantly different from other PBDS concepts.

The references of the selected articles have then been reviewed to add relevant related publications to the analysis.

Given the low number of prospective studies with long-term follow-up the decision has been taken to keep the retrospective studies and the short-term studies, with a mean follow-up higher than 12 months, in the analysis.

Within the 279 publications retrieved by the Medline search, and the additional references, a total of 46 clinical studies were included in the review process.

\section{Statistics}

Unpaired $t$ test was used to compare cohorts following the study design.

\section{Observed Parameters}

The parameters observed by each author of the selected articles differ from one article to another. The publications have been classified given the following parameters.

- Clinical outcomes (ODI, VAS, satisfaction).

- Adjacent segment protection.

- Device-related complications (breakages, loosening).

- Revision surgeries.

Some of the included papers present a comparison between a dynamic device group and a control group. These additional data will be used in the Discussion section.

\section{RESULTS}

\section{Devices}

The 11 different PBDS devices included in the review are listed in Table 1 and the available data in Table 2.

\section{Dynamic Versus Hybrid Use}

Most of the devices were used as pure dynamic constructs for spine segmental stabilization. There were 8 papers dealing with hybrid devices (Table 3). Three of these studies ${ }^{16,29,47}$ compared the 2 versions of the same device: pure dynamic versus hybrid construct. Among the total 2026 patients included in this systematic review, only 145 had a hybrid construct. Except for 2 papers ${ }^{24,29}$ the distinction between dynamic and hybrid use was made for the analysis of the results.

\section{Retrospective Versus Prospective Study}

Among the 46 studies 18 were prospective, dealing with a global amount of 641 patients. A total of 16 additional studies were retrospective but dealt with consecutive patients' cohorts: 776 patients were included in this group. The 609 remaining patients were included in retrospective nonconsecutive studies or in studies where the information necessary to conclude was missing (Table 4). Four studies dealt with a comparison with fusion, ${ }^{4,11,32,46}$ 1 study compared dynamic stabilization with noninstrumented surgery, ${ }^{17}$ and 1 study addressed the issue of performing or not an additional decompression gesture. ${ }^{31}$

\section{Indications}

The most encountered indications for surgery were clinical symptoms associated with degenerative disk diseases, spinal stenosis, disk herniation, segmental instability, or low-grade spondylolisthesis. More scarcely, the devices were used for revision surgeries because of adjacent segment pathology or for degenerative scoliosis.

The additional decompressive gestures did not always describe in detail as to what causes an issue in the analysis of the outcomes, especially in terms of pain relieving.

\section{Clinical Outcomes}

In this clinical review, 41 studies out of 46 dealt with self-assessment of the clinical outcomes, reporting VAS or ODI scores. Ten studies mentioned patient satisfaction 


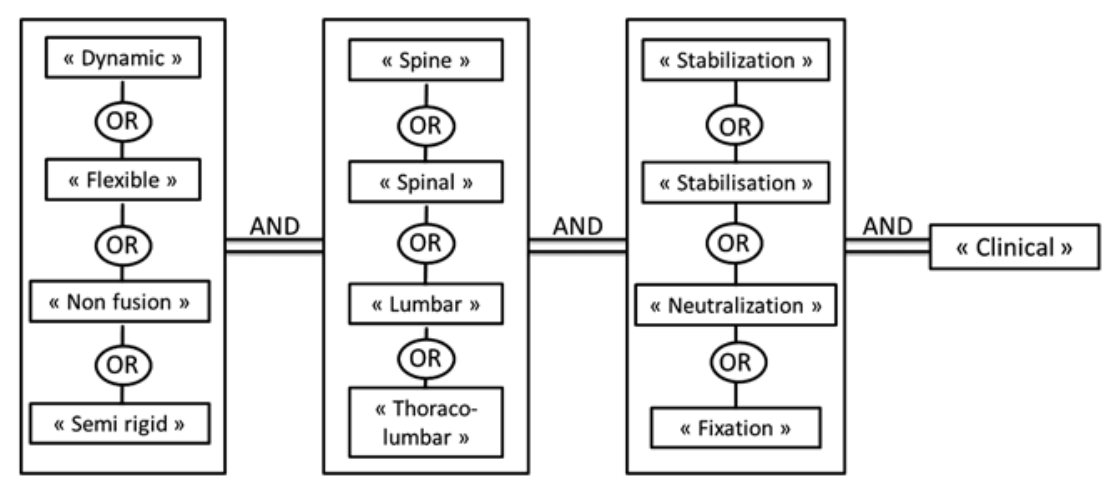

FIGURE 1. Query for the systematic Medline search on the words included in the title or in the abstract of the paper.

through the answer to the question "Would you choose to undergo the same operation now knowing the results?"

The results of the VAS are presented in Table 5. Scores for global VAS were given in 17 studies concerning 747 patients. The mean score varied from 5.8 to 8.6 before surgery, and from 0.8 to 4.2 at a last follow-up of 29.7 months on an average. For 754 other patients (included in 18 studies) VAS scores were separated according to back pain and leg pain. Overall, the mean score for VAS-back varied from 5.4 to 8.3 preoperatively, and from 1.9 to 5.7 at a last follow-up of 28.0 months on an average. The mean score for VAS-leg varied from 4.2 to 8.4 preoperatively, and from 1.0 to 4.7 at last follow-up.

ODI scores were reported in 33 studies concerning 1573 patients. The mean value was comprised between $24.7 \%$ and $79.6 \%$ before surgery. At a last follow-up of 33.9 months on an average, ODI mean score was between $3.0 \%$ and $49.9 \%$. ODI scores are detailed in Table 5 .

In the 10 studies dealing with patient's satisfaction analysis, $83.4 \%$ of 635 patients answered they would choose to undergo the same operation. Those patients had a mean hindsight of 43.6 months at the time of their answer. The values were comprised between $68 \%{ }^{15}$ and $94 \%{ }^{5}$

No statistically significant difference has been found for any clinical score between the prospective and the retrospective studies.

\section{ASD}

About one out of 3 studies addressed the occurrence of ASD. As the clinical symptoms triggered by ASD were not always detailed, distinction was made between ASD triggering revision surgery and radiographic ASD
(Table 6). Rates of symptomatic ASD are obviously lower than radiographic occurrence. Among the different papers, there was a wide range of radiographic ASD occurrence, ranging from $0 \%$ to $34 \%$ representing a mean of $16 \%$ (out of 333 patients, with a mean hindsight of $51 \mathrm{mo}$ ). As far as revision surgery for ASD is concerned, the mean occurrence was $3.4 \%$, calculated out of 770 patients at a mean follow-up of 38 months. Even if the global tendency is an increasing rate of ASD with an increasing follow-up, the correlation between mean follow-up and rates of ASD is very low $\left(R^{2}=0.14\right.$, Fig. 2$)$. No statistically significant difference has been found between retrospective studies and prospective studies concerning the occurrence of ASD.

\section{Mechanical Failure of the Implant}

Postoperative complications related to the mechanical failures of the device (rod or screw breakages and screw loosening) are reported in Table 6 . There was a wide range of rod breakages varying from $0 \%$ to $30 \%$. Predictably enough, no rod breakages were reported for Dynesys because it is radiotransparent. Apart from this device, the global rate of rod breakage was $2.2 \%$ (13 out of 610 patients).

Regarding screw breakage, the mean global rate was $1.6 \%$ (29 out of 1788 patients).

The mean global rate of screw loosening was $10.1 \%$ (163 cases out of 1608 patients) but within a wide range of occurrence from $0 \%$ to $72 \%$.

In this review, the rates of mechanical complication seem not to be correlated with the follow-up. There was no statistically significant difference concerning the occurrence

TABLE 1. Pedicle-based Dynamic Stabilization Devices for Reach Results Are Reported in This Review

\begin{tabular}{llcl}
\hline "Spring-like" metallic devices & & Devices with a metallic core and a PCU sleeve \\
Accuflex & Globus Medical, Audubon, PA & Agile & Medtronic Sofamor Danek, Memphis, TN \\
BioFlex & Biospine, Seoul, Korea & Flex + & Spinevision, Antony, France \\
$\begin{array}{l}\text { Dream elastic rod system } \\
\text { Hinged-screw devices }\end{array}$ & Dream STS, Seoul, Korea & Nflex & Synthes Spine, West Chester, PA \\
& & $\begin{array}{c}\text { Other dynamic } \\
\text { devices }\end{array}$ & \\
$\begin{array}{l}\text { Safinaz } \\
\text { Cosmic }\end{array}$ & Medikon AS, Turkey & Isobar & Scient'X Alphatec Spine USA, Maitland, FL \\
$\begin{array}{l}\text { PCU + ligament } \\
\text { Dynesys }\end{array}$ & Ulrich Gmbh and Co. KG, Ulm, Germany & Isolock & Scient'X Alphatec Spine USA \\
\hline
\end{tabular}




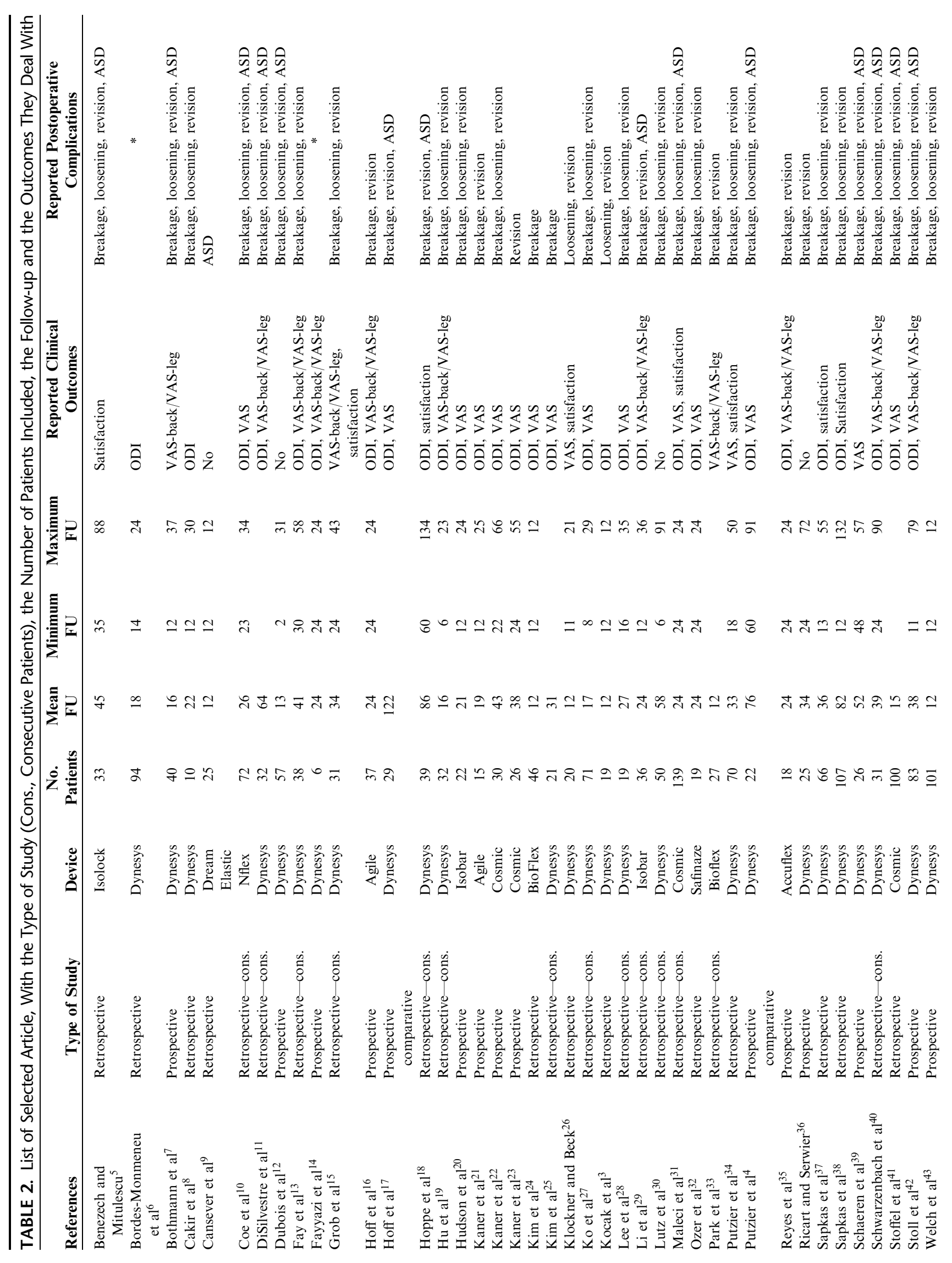


TABLE 3. Number of Patients Included in Studies Reporting the Use of the PBDS Device in a Hybrid Manner

\begin{tabular}{|c|c|c|c|}
\hline \multirow[b]{2}{*}{ References } & \multirow[b]{2}{*}{ Device } & \multicolumn{2}{|c|}{ Type of Construct } \\
\hline & & Pure Dynamic & Hybrid \\
\hline Hoff et $\mathrm{al}^{16}$ & Agile & 17 & 20 \\
\hline Hudson et $\mathrm{al}^{20}$ & Isobar & 0 & 22 \\
\hline Kaner et $\mathrm{al}^{21}$ & Agile & 0 & 15 \\
\hline Kim et $\mathrm{al}^{24}$ & Bioflex & $?$ & $?$ \\
\hline Li et $\mathrm{al}^{29}$ & Isobar & 23 & 13 \\
\hline Putzier et $\mathrm{al}^{4}$ & Dynesys & 0 & 22 \\
\hline Schwarzenbach et $\mathrm{al}^{40}$ & Dynesys & 0 & 31 \\
\hline Zagra et $\mathrm{al}^{47}$ & Flex + & 10 & 22 \\
\hline
\end{tabular}

of complications between retrospective and prospective studies.

\section{Revision Surgery}

The number of patients who underwent a revision surgery is reported in Table 6. Overall, the mean global rate of revision was $9.4 \%$ including different rationales for revision surgeries (complications, device failure, or ASD). Rates of symptomatic complications leading to revision surgeries are lower than rates of complications seen on imaging but we cannot know what will be the evolution on the long term, for instance for patients with signs of degeneration at mid-term follow-up.

\section{DISCUSSION}

As nonfusion devices are the subject of growing questioning, our aim was to perform a review of the clinical literature to understand the outcomes and complications linked with this family of devices. As many meta-analysis, the main limitations of this study were the high variability of protocols and the lack of long-term randomized controlled studies, limiting conclusions especially concerning the degeneration of adjacent segments, which is the main endpoint of dynamic devices. Moreover, additional surgical decompressions were sometimes performed or the surgical procedure not detailed, making it difficult to distinguish the benefits of the decompression from the benefits of the instrumentation. Last, the variability of designs available on the market and the major differences from one device to another has to be kept in mind even if all the results are here summarized together.

Nevertheless, despite those limitations, our review enabled us to highlight some key points in the understanding of dynamic stabilization outcomes.

TABLE 4. Type of Study

\begin{tabular}{lcc}
\hline Type & Studies & Patients \\
\hline Prospective & 15 & 555 \\
Prospective comparative & 3 & 86 \\
Retrospective & 12 & 609 \\
Retrospective consecutive & 16 & 776 \\
Total & 46 & 2026 \\
\hline
\end{tabular}


TABLE 5. Clinical Outcomes Reported in Each Publication (Mean Scores Assessed Preoperatively and at Last FU)

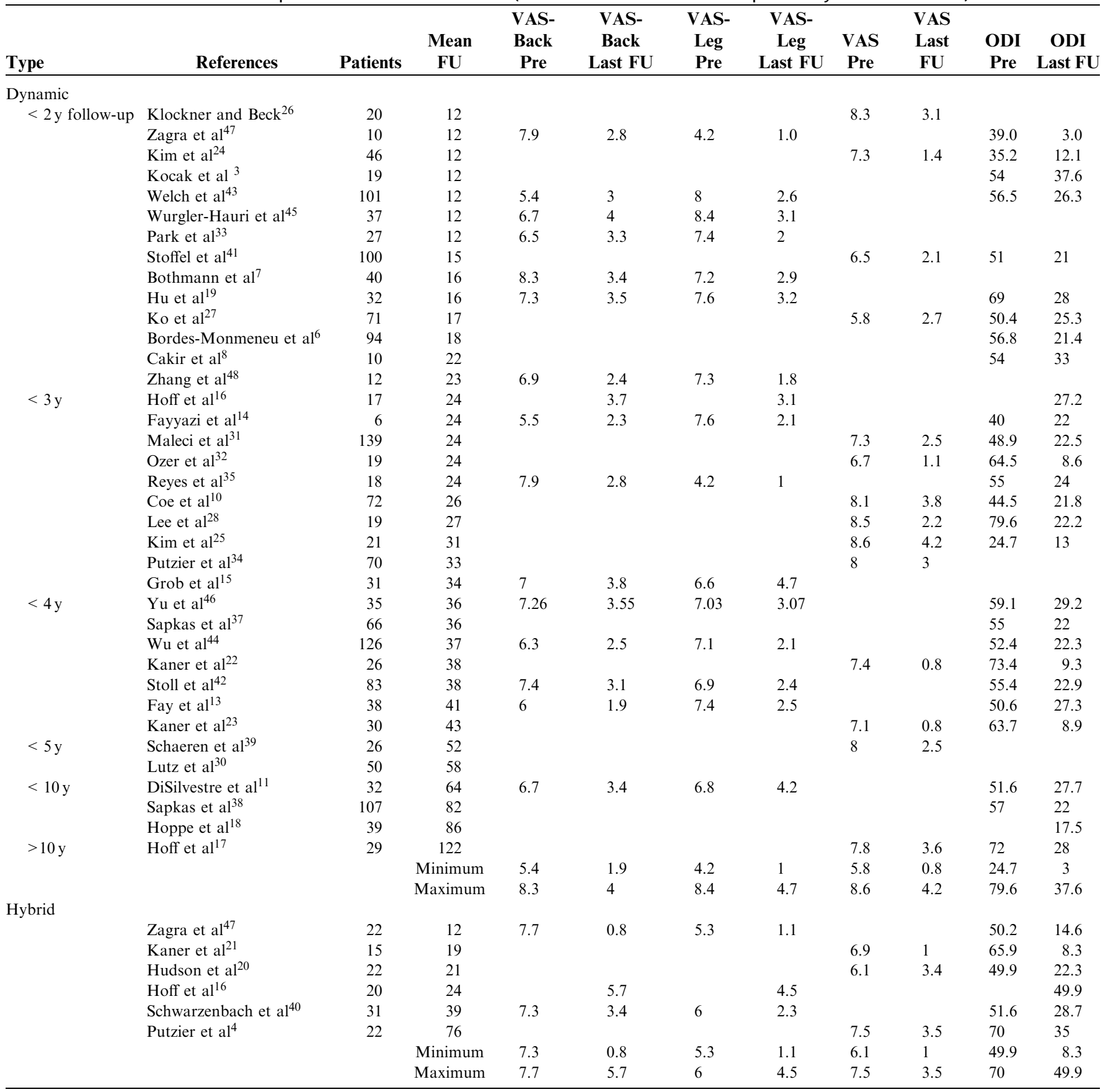

FU indicates follow-up; ODI, Oswestry Disability Index; VAS, visual analog scale.

\section{Clinical Outcomes}

Although VAS remains a self-assessment of the pain with all bias implied, a significant reduction of the pain was underlined in every study. The ODI can be analyzed following 5 categories ${ }^{49}$ : minimal disability $(0 \%-20 \%)$, moderate disability $(20 \%-40 \%)$, severe disability $(40 \%-60 \%)$, crippled $(60 \%-80 \%)$, bed-bound $(80 \%-100 \%)$. On an average, the mean ODI score at last follow-up corresponds to a moderate disability. Ozer et al's ${ }^{32}$ retrospective study and Putzier et al's ${ }^{4}$ prospective comparative study between fusion and dynamic stabilization did not show superiority of any device. Only $\mathrm{Yu}$ et al's ${ }^{46}$ retrospective comparison between Dynesys and PLIF underlined a significantly better clinical improvement for Dynesys group. Carreon et $\mathrm{al}^{50}$ performed a meta-analysis of the literature about prospective studies comparing fusion with conservative 
TABLE 6. Occurrence of Device-related Complications and Corresponding Rates

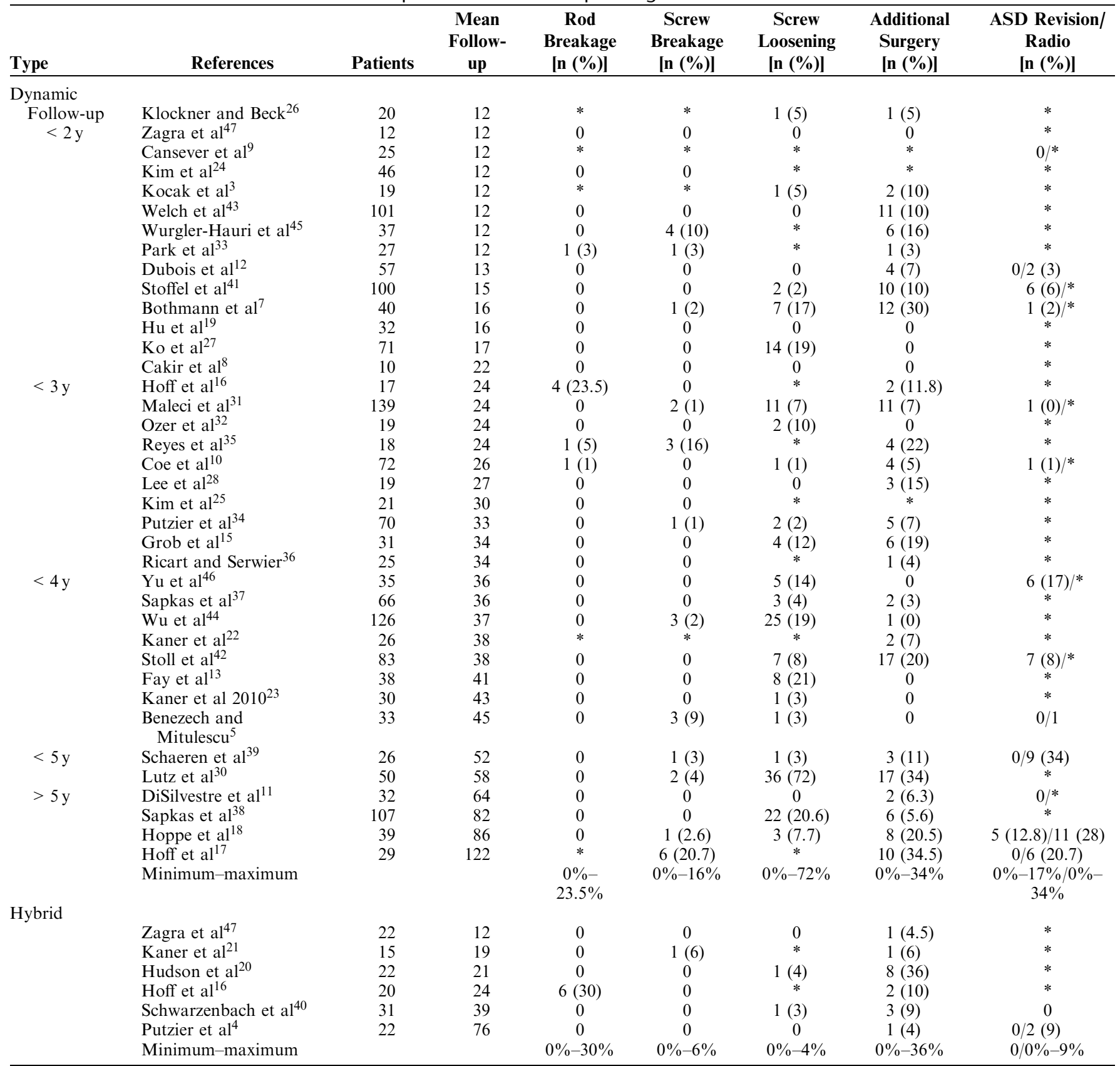

*Not mentioned by the author.

ASD indicates adjacent segment degeneration.

treatments. Preoperative score was on an average $45.5 \%$ (range, 42.0-48.4). The improvement was $18.3 \%$ (range, 8.9-24.5) in the surgical group and 8.1\% (range, 2.8-13.3) in the conservative group. In this review the mean preoperative score was a little bit higher $(53.8 \%$; range, 24.7-79.6) and the mean improvement was $31.8 \%$ (range, 11.7-64.1). If we only keep the 5 studies with a mean preoperative ODI comprised between $40 \%$ and $50 \%$ (307 patients are concerned) the mean preoperative ODI is
$46.6 \%$ (range, 40-49.9) and the mean improvement is $26.0 \%$ (range, $18-38.8$ ). This seems as a higher improvement than for fusion and conservative care but patients cohorts and indications should be analyzed in details to conclude.

Moreover, $83.4 \%$ of interviewed patients would choose to undergo the same procedure again, now knowing the results, which indicates that patients are satisfied. 


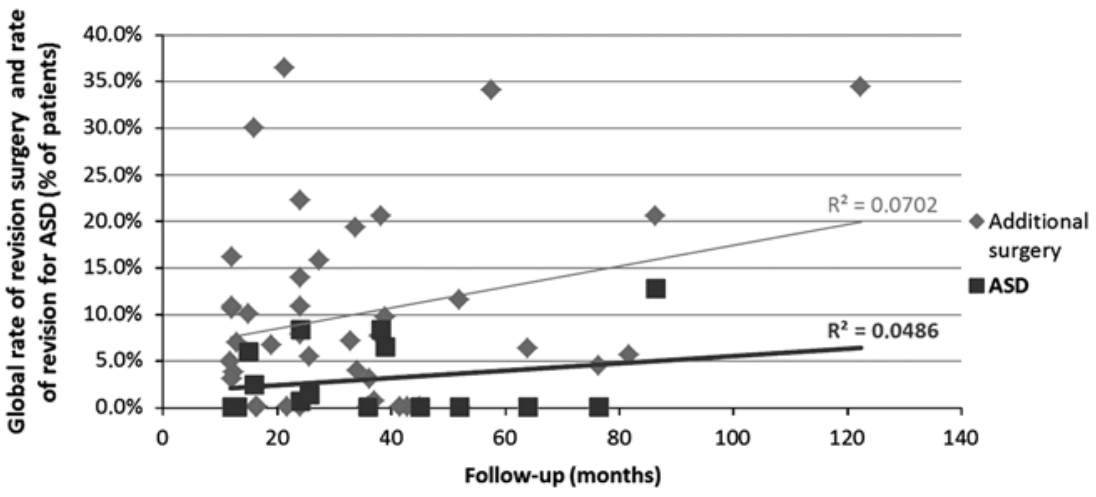

FIGURE 2. Global rates of revision and rates of revision for adjacent segment degeneration reported given the mean follow-up for studies addressing those topics only (linear correlation coefficient $R^{2}$ are indicated).

\section{Influence on Adjacent Segment}

Even if adjacent segment protection is one of the main purposes of dynamic stabilization, only 16 studies mentioned the issue of ASD. A total of $16 \%$ of patients were reported as showing ASD, not always symptomatic still the accurate definition remains very controversial. However, the global rate of revision for ASD (3.4\% at $38 \mathrm{mo}$ ) is lower than the rates reported by Park et $\mathrm{al}^{51}$ in their literature review $(5.2 \%-18.5 \%$ of symptomatic ASD even with only 60 mo of follow-up). In their prospective comparative study between dynamic stabilization and noninstrumented decompression Hoff et $\mathrm{al}^{17}$ highlighted a significantly higher rate of ASD for Dynesys group and Putzier et $\mathrm{al}^{4}$ observed a higher rate of radiographic ASD in the fusion group.

Surprisingly enough, no real relationship between the follow-up and the rate of revision for ASD seem to arise through this review, this might be explained by the discrepancies between the different studies (cohort size, indications, surgical techniques, etc.) Moreover, we can wonder how the $16 \%$ of patients with radiographic signs of ASD will evolve in the coming years. Among the few studies with a follow-up higher than 60 months, radiographic ASD was between $7 \%{ }^{4}$ and $28 \%{ }^{18}$ and revision surgery between $0 \%{ }^{4,11}$ and $12.8 \% .^{18}$ Adjacent segment pathologies and the influence of instrumentation as compared with natural history are still a moot point. ${ }^{52}$

The issue of motion preservation has been assessed in a few studies of this selection. ${ }^{13,27,28,35}$ Unfortunately, no study looked for a correlation between the occurrence of ASD and the motion of the instrumented segment.

Beyond the use of a soft stabilization transferring fewer loads than fusion, the key for the reduction of loads is an "economical" sagittal balance. ${ }^{53,54}$ "Noneconomical fusion," with for instance hypolordosis, more accurately than "fusion," could be charged with an increased ASD. Correlations between the sagittal alignment changes and the occurrence of ASD have been underlined by Kumar et $\mathrm{al}^{55}$ in their series where $36.1 \%$ of patients had radiographic ASD and $16.8 \%$ of patients needed revision surgery at 5.2 years. Although assessment of sagittal alignment has a critical importance, measurements are rarely reported in clinical papers about dynamic stabilization.

Discrepancies between radiographic and symptomatic degeneration leading to revision surgery are in accordance with the rates of degenerated segments observed in asymptomatic population, especially with an increasing age. ${ }^{56,57}$

\section{Device-related Complications}

The overall amount of device breakages (screw or rod) is around $2.3 \%$. As far as rigid devices are concerned, Esses et $\mathrm{al}^{58}$ reported an overall rate of screw breakage of $2.9 \%$. The design of the device is obviously a critical parameter for mechanical and biomechanical behavior; for instance, a too high rate of breakage triggered the withdrawal from the market of 1 dynamic device. ${ }^{16}$

The $9.6 \%$ of patients who showed signs of screw loosening did not always had clinical symptoms. Nevertheless it has been highlighted that screw loosening can bring about late infections implying revision surgeries. ${ }^{30}$ The osseous quality has a direct impact on screw loosening $^{59}$ but was rarely reported. A literature review about Dynesys ${ }^{3}$ found between $0 \%$ and $17 \%$ of screw loosening with a maximum rate of revision surgery of $12.9 \%$. The stiffness of the devices ${ }^{60,61}$ might be positively correlated with the rates of screw loosening. In contrary, a high stiffness might also account for the good short-term clinical outcomes as it preserves the preoperative distraction thus unloading the anatomic structures. This underlines that a good compromise in terms of stiffness has to be determined. With the current knowledge of the biomechanical behavior of the instrumented lumbar spine, several influencing parameters for mechanical failure can be suggested:

- First, the design of dynamic implants that varies a lot from one to another. For instance, it has been suggested that the axial stiffness has a direct impact on the motion of the segment. ${ }^{62}$ The importance of shear stresses on devices is also becoming more and more pointed to. ${ }^{16}$ Moreover in vitro testing underlines that shear resistance decreases with the degeneration of the segment, ${ }^{63}$ which make shear resistance a key point 
of the device failure. This also raises the question of implant design validation before marketing.

- Then the preoperative surgical technique and the preconstraining of the device when locked in the screws might increase the applying loads. As fusion is not expected to occur after dynamic stabilization, the devices are exposed as long as they are implanted.

- The patient's pathology and the related instability may also trigger shear loading of the device especially in the sagittal plane.

- As described by Legaye and Duval-Beaupere, ${ }^{64}$ there is a critical correlation between balance and muscular forces occurring to compensate the gravity. This obviously implies a difference in loads applied on the device and transfer on adjacent segments. What is more, in vitro studies demonstrated that the dynamic stabilization triggered a posterior shift of the axis of rotation. ${ }^{60}$ These changes can have different influences given the preoperative balance of the patient. The structures overloaded vary given the back type of the patient as described by Roussouly et al. ${ }^{65}$ For instance a high lordosis predisposes the patient to overloading of the posterior structures. This type might also induce overloading of the instrumentation in shear. Last, the flexibility of the device might prevent from achieving the expected segmental lordosis thus triggering hyperlordosis at the adjacent level. Umehara et $\mathrm{al}^{66}$ found through an in vitro study that hypolordosis increased the loading on posterior structures of the adjacent segment. This issue has also been addressed in a radiologic comparative study between 2 dynamic devices ${ }^{67}$ showing that hybrid stabilization might be interesting for long constructs to better preserve lordosis.

- Last, patient's daily activity or punctual overloading conditions (sports, fall, etc.) also play their part in the loading of the device.

This literature review gives a global overview of short-term clinical outcomes of PBDS devices that seem to be noninferior to fusion devices in terms of clinical improvement and postoperative complications. Despite the differences between design choices, similar biomechanical issues can arise. More and more evidences show that the success of the surgery might be patient specific. The indications for dynamic stabilization have to be reconsidered and a particular attention has to be paid to patient condition such as spine balance or level of instability to increase the success rates of dynamic stabilization. Finally, the understanding of the biomechanics, in particular the impact on adjacent segment has to be continued and analyzed in the light of long-term clinical outcomes.

\section{REFERENCES}

1. Sengupta DK. Dynamic stabilization devices in the treatment of low back pain. Orthop Clin North Am. 2004;35:43-56.

2. Barrey CY, Ponnappan RK, Song J, et al. Biomechanical evaluation of pedicle screw-based dynamic stabilization devices for the lumbar spine: a systematic review. SAS J. 2008;2:159-170.

3. Kocak T, Cakir B, Reichel H, et al. Screw loosening after posterior dynamic stabilization - review of the literature. Acta Chir Orthop Traumatol Cech. 2010;77:134-139.
4. Putzier M, Hoff E, Tohtz S, et al. Dynamic stabilization adjacent to single-level fusion: part II. No clinical benefit for asymptomatic, initially degenerated adjacent segments after 6 years follow-up. Eur Spine J. 2010;19:2181-2189.

5. Benezech J, Mitulescu A. Retrospective patient outcome evaluation after semi-rigid stabilization without fusion for degenerative lumbar instability. Eur J Orthop Surg Traumatol. 2007;17:227-234.

6. Bordes-Monmeneu M, Bordes-Garcia V, Rodrigo-Baeza F, et al. System of dynamic neutralization in the lumbar spine: experience on 94 cases. Neurocirugia (Astur). 2005;16:499-506.

7. Bothmann M, Kast E, Boldt GJ, et al. Dynesys fixation for lumbar spine degeneration. Neurosurg Rev. 2008;31:189-196.

8. Cakir B, Richter M, Huch K, et al. Dynamic stabilization of the lumbar spine. Orthopedics. 2006;29:716-722.

9. Cansever T, Civelek E, Kabatas S, et al. Dysfunctional segmental motion treated with dynamic stabilization in the lumbar spine. World Neurosurg. 2011;75:743-749.

10. Coe JD, Kitchel SH, Meisel HJ, et al. NFlex dynamic stabilization system: two-year clinical outcomes of multi-center study. $J$ Korean Neurosurg Soc. 2012;51:343-349.

11. Di Silvestre M, Lolli F, Bakaloudis G. Degenerative lumbar scoliosis in elderly patients: dynamic stabilization without fusion versus posterior instrumented fusion. Spine J. 2012;14:1-10.

12. Dubois G, De Germay B, Scharer N, et al. Dynamic neutralization: a new concept for restabilization of the spine. Rivista di Neuroradiologia. 1999;12(suppl 1):175-176.

13. Fay LY, Wu JC, Tsai TY, et al. Dynamic stabilization for degenerative spondylolisthesis: evaluation of radiographic and clinical outcomes. Clin Neurol Neurosurg. 2013;115:535-541.

14. Fayyazi AH, Ordway NR, Park SA, et al. Radiostereometric analysis of postoperative motion after application of dynesys dynamic posterior stabilization system for treatment of degenerative spondylolisthesis. J Spinal Disord Tech. 2010;23:236-241.

15. Grob D, Benini A, Junge A, et al. Clinical experience with the Dynesys semirigid fixation system for the lumbar spine: surgical and patient-oriented outcome in 50 cases after an average of 2 years. Spine (Phila Pa 1976). 2005;30:324-331.

16. Hoff E, Strube P, Gro C, et al. Which radiographic parameters are linked to failure of a dynamic spinal implant? Clin Orthop Relat Res. 2012;470:1834-1846.

17. Hoff E, Strube P, Rohlmann A, et al. Sequestrectomy with additional transpedicular dynamic stabilization for the treatment of lumbar disc herniation - no clinical benefit after 10 years followup. Spine (Phila Pa 1976). 2013;38:887-895.

18. Hoppe S, Schwarzenbach O, Aghayev E, et al. Long-term outcome after monosegmental L4/5 stabilization for degenerative spondylolisthesis with the Dynesys device. J Spinal Disord Tech. 2012. [Epub ahead of print].

19. Hu Y, Gu YJ, Xu RM, et al. Short-term clinical observation of the Dynesys neutralization system for the treatment of degenerative disease of the lumbar vertebrae. Orthop Surg. 2011;3:167-175.

20. Hudson WRS, Gee JE, Billys JB, et al. Hybrid dynamic stabilization with posterior spinal fusion in the lumbar spine. SAS J. 2011;5: 36- 43 .

21. Kaner T, Sasani M, Oktenoglu T, et al. Utilizing dynamic rods with dynamic screws in the surgical treatment of chronic instability: a prospective clinical study. Turk Neurosurg. 2009;19:319-326.

22. Kaner T, Sasani M, Oktenoglu T, et al. Clinical outcomes of degenerative lumbar spinal stenosis treated with lumbar decompression and the Cosmic "semi-rigid" posterior system. SAS J. 2010;4:99-106.

23. Kaner T, Dalbayrak S, Oktenoglu T, et al. Comparison of posterior dynamic and posterior rigid transpedicular stabilization with fusion to treat degenerative spondylolisthesis. Orthopedics. 2010;33:309.

24. Kim YS, Zhang HY, Moon BJ, et al. Nitinol spring rod dynamic stabilization system and Nitinol memory loops in surgical treatment for lumbar disc disorders: short-term follow up. Neurosurg Focus. 2007:22:E10

25. Kim CH, Chung CK, Jahng TA. Comparisons of outcomes after single or multilevel dynamic stabilization: effects on adjacent segment. J Spinal Disord Tech. 2011;24:60-67. 
26. Klockner C, Beck A. Polysegmental Dynesys system. Orthopade. 2011;40:156-161.

27. Ko CC, Tsai HW, Huang WC, et al. Screw loosening in the Dynesys stabilization system: radiographic evidence and effect on outcomes. Neurosurg Focus. 2010;28:E10.

28. Lee SE, Park SB, Jahng TA, et al. Clinical experience of the dynamic stabilization system for the degenerative spine disease. $J$ Korean Neurosurg Soc. 2008:43:221-226.

29. Li Z, Li F, Yu S, et al. Two-year follow-up results of the Isobar TTL Semi-Rigid Rod System for the treatment of lumbar degenerative disease. J Clin Neurosci. 2013;20:394-399.

30. Lutz JA, Otten P, Maestretti G. Late infections after dynamic stabilization of the lumbar spine with Dynesys. Eur Spine J. 2012;21:2573-2579.

31. Maleci A, Sambale RD, Schiavone M, et al. Nonfusion stabilization of the degenerative lumbar spine. J Neurosurg Spine. 2011;15:151-158.

32. Ozer AF, Crawford NR, Sasani M, et al. Dynamic lumbar pedicle screw-rod stabilization: two-year follow-up and comparison with fusion. Open Orthop J. 2010;4:137-141.

33. Park SC, Yoon SH, Hong YP, et al. Minimum 2-year follow-up result of degenerative spinal stenosis treated with interspinous $u$ (coflex). J Korean Neurosurg Soc. 2009;46:292-299.

34. Putzier M, Schneider SV, Funk J, et al. Application of a dynamic pedicle screw system (Dynesys) for lumbar segmental degenerations - comparison of clinical and radiological results for different indications. Z Orthop Ihre Grenzgeb. 2004;142:166-173.

35. Reyes-Sanchez A, Zarate-Kalfopulos B, Ramirez-Mora I, et al. Posterior dynamic stabilization of the lumbar spine with the Accuflex rod system as a stand-alone device: experience in 20 patients with 2-year follow-up. Eur Spine J. 2010;19:2164-2170.

36. Ricart O, Serwier JM. Dynamic stabilisation and compression without fusion using Dynesys for the treatment of degenerative lumbar spondylolisthesis: a prospective series of 25 cases. Rev Chir Orthop Reparatrice Appar Mot. 2008;94:619-627.

37. Sapkas GS, Themistocleous GS, Mavrogenis AF, et al. Stabilization of the lumbar spine using the dynamic neutralization system. Orthopedics. 2007;30:859-865.

38. Sapkas G, Mavrogenis AF, Starantzis KA, et al. Outcome of a dynamic neutralization system for the spine. Orthopedics. 2012;35:e1497-e1502.

39. Schaeren S, Broger I, Jeanneret B. Minimum four-year follow-up of spinal stenosis with degenerative spondylolisthesis treated with decompression and dynamic stabilization. Spine (Phila Pa 1976). 2008;33:E636-E642.

40. Schwarzenbach O, Berlemann U. Dynamic posterior stabilization with the pedicle screw system DYNESYS(R). Oper Orthop Traumatol. 2010;22:545-557.

41. Stoffel M, Behr M, Reinke A, et al. Pedicle screw-based dynamic stabilization of the thoracolumbar spine with the Cosmic-system: a prospective observation. Acta Neurochir (Wien). 2010;152:835-843.

42. Stoll TM, Dubois G, Schwarzenbach O. The dynamic neutralization system for the spine: a multi-center study of a novel non-fusion system. Eur Spine J. 2002;11(suppl 2):S170-S178.

43. Welch WC, Cheng BC, Awad TE, et al. Clinical outcomes of the Dynesys dynamic neutralization system: 1-year preliminary results. Neurosurg Focus. 2007;22:E8.

44. Wu JC, Huang WC, Tsai HW, et al. Pedicle screw loosening in dynamic stabilization: incidence, risk, and outcome in 126 patients. Neurosurg Focus. 2011;31:E9.

45. Wurgler-Hauri CC, Kalbarczyk A, Wiesli M, et al. Dynamic neutralization of the lumbar spine after microsurgical decompression in acquired lumbar spinal stenosis and segmental instability. Spine (Phila Pa 1976). 2008;33:E66-E72.

46. Yu SW, Yen $\mathrm{CY}, \mathrm{Wu} \mathrm{CH}$, et al. Radiographic and clinical results of posterior dynamic stabilization for the treatment of multisegment degenerative disc disease with a minimum follow-up of 3 years. Arch Orthop Trauma Surg. 2012;132:583-589.

47. Zagra A, Minoia L, Archetti M, et al. Prospective study of a new dynamic stabilisation system in the treatment of degenerative discopathy and instability of the lumbar spine. Eur Spine J. 2012;21(suppl 1):S83-S89.

48. Zhang HY, Park JY, Cho BY. The BioFlex system as a dynamic stabilization device: does it preserve lumbar motion? $J$ Korean Neurosurg Soc. 2009;46:431-436.

49. Fairbank JC, Couper J, Davies JB, et al. The Oswestry low back pain disability questionnaire. Physiotherapy. 1980;66:271-273.

50. Carreon LY, Glassman SD, Howard J. Fusion and nonsurgical treatment for symptomatic lumbar degenerative disease: a systematic review of Oswestry Disability Index and MOS short form-36 outcomes. Spine J. 2008;8:747-755.

51. Park P, Garton HJ, Gala VC, et al. Adjacent segment disease after lumbar or lumbosacral fusion: review of the literature. Spine (Phila Pa 1976). 2004;29:1938-1944.

52. Radcliff KE, Kepler CK, Jakoi A, et al. Adjacent segment disease in the lumbar spine following different treatment interventions. Spine J. 2013;13:1229-1349.

53. Legaye J, et al. Pelvic incidence: a fundamental pelvic parameter for three-dimensional regulation of spinal sagittal curves. Eur Spine J. 1998;7:99-103.

54. Legaye J. The femoro-sacral posterior angle: an anatomical sagittal pelvic parameter usable with dome-shaped sacrum. Eur Spine J. 2007;16:219-225.

55. Kumar MN, Baklanov A, Chopin D. Correlation between sagittal plane changes and adjacent segment degeneration following lumbar spine fusion. Eur Spine J. 2001;10:314-319.

56. Pfirrmann CW, Metzdorf A, Elfering A, et al. Effect of aging and degeneration on disc volume and shape: a quantitative study in asymptomatic volunteers. J Orthop Res. 2006;24:1086-1094.

57. Miller JA, Schmatz C, Schultz AB. Lumbar disc degeneration: correlation with age, sex, and spine level in 600 autopsy specimens. Spine (Phila Pa 1976). 1988;13:173-178.

58. Esses SI, Sachs BL, Dreyzin V. Complications associated with the technique of pedicle screw fixation. A selected survey of ABS members. Spine (Phila Pa 1976). 1993;18:2231-2238; discussion $2238-2239$.

59. Wu ZX, Gong FT, Liu L, et al. A comparative study on screw loosening in osteoporotic lumbar spine fusion between expandable and conventional pedicle screws. Arch Orthop Trauma Surg. 2012;132:471-476.

60. Niosi CA, Zhu QA, Wilson DC, et al. Biomechanical characterization of the three-dimensional kinematic behaviour of the Dynesys dynamic stabilization system: an in vitro study. Eur Spine J. 2006;15:913-922.

61. Schmoelz W, Huber JF, Nydegger T, et al. Dynamic stabilization of the lumbar spine and its effects on adjacent segments: an in vitro experiment. J Spinal Disord Tech. 2003;16:418-423.

62. Schmidt H, Heuer F, Wilke HJ. Which axial and bending stiffnesses of posterior implants are required to design a flexible lumbar stabilization system? J Biomech. 2009;42:48-54.

63. Bisschop A, Mullender MG, Kingma I, et al. The impact of bone mineral density and disc degeneration on shear strength and stiffness of the lumbar spine following laminectomy. Eur Spine J. 2012; 21:530-536.

64. Legaye J, Duval-Beaupere G. Gravitational forces and sagittal shape of the spine. Clinical estimation of their relations. Int Orthop. 2008;32:809-816.

65. Roussouly P, Gollogly S, Berthonnaud E, et al. Classification of the normal variation in the sagittal alignment of the human lumbar spine and pelvis in the standing position. Spine (Phila Pa 1976). 2005;30:346-353.

66. Umehara S, Zindrick MR, Patwardhan AG, et al. The biomechanical effect of postoperative hypolordosis in instrumented lumbar fusion on instrumented and adjacent spinal segments. Spine (Phila Pa 1976). 2000;25:1617-1624.

67. Chen H, Charles YP, Bogorin I, et al. Influence of 2 different dynamic stabilization systems on sagittal spinopelvic alignment. J Spinal Disord Tech. 2011;24:37-43. 